\title{
O Círculo de Bakhtin e o Idealismo Alemão: relações entre pensamento e língua
}

\author{
Taciane Domingues \\ Universidade de São Paulo (USP), São Paulo, São Paulo, Brasil \\ tacianedomingues@gmail.com
}

DOI: http://dx.doi.org/10.21165/el.v46i2.1642

\begin{abstract}
Resumo
Neste artigo, investigamos a relação entre pensamento e língua nas escolas marxista russa e idealista alemã. Partimos da obra Marxismo e Filosofia da Linguagem: problemas fundamentais do método sociológico na ciência da linguagem, na qual a Filologia Idealista Moderna de Karl Vossler, cuja filosofia está presente em Gesammelte Aufsätze zur Sprachphilosophie (Escritos Reunidos para uma Filosofia da Linguagem) e a filosofia de Wilhelm von Humboldt são citadas como tese a partir da qual, confrontada à sua antítese, a síntese se apresenta como a filosofia marxista. O grande esquematizador da filosofia idealista, G. W. F. Hegel, foi abordado a fim de contextualizar a filosofia da linguagem de base idealista. Por fim, ao analisarmos as influências da escola alemã em MFL, observamos uma inversão da dialética idealista no seu ponto de origem, isto é, a consciência não imprime suas leis ao mundo; ao contrário, a ideologia social adentra a consciência individual por meio dos signos ideológicos.
\end{abstract}

Palavras-chave: língua; filosofia da linguagem; marxismo; idealismo alemão; Círculo de Bakhtin.

Bakhtin Circle and the German Idealism: relations between thought and language

\begin{abstract}
In this article, the relations between language and thought among the Russian Marxist and the German idealist schools were investigated. Our basis was Marxism and the Philosophy of Language, in which Karl Vossler's German school Idealistische Neuphilologie (Modern Idealist Philology) presented in Gesammelte Aufsätze zur Sprachphilosophie (Gathered Writings for a Philosophy of Language) and Wilhelm von Humboldt's philosophy are mentioned as the thesis that, compared to the antithesis, results in the synthesis represented by the Marxist philosophy. The great idealist philosopher G. W. F. Hegel was also discussed to bring the German idealist philosophy of language into context. When analyzing the German school influence on Bakhtin/Volochinov's aforementioned work, it is possible to note an inversion on the idealist dialectic. Instead of the consciousness printing its laws onto the world, social ideology shapes the subject's consciousness through the ideological sign.
\end{abstract}

Keywords: language; philosophy of language; Marxism; German idealism; Bakhtin Circle.

\section{Introdução e justificativa}

Na obra Marxismo e filosofia da linguagem: problemas fundamentais do método sociológico na ciência da linguagem (doravante MFL), Bakhtin/Volochinov (2014) lançaram as bases de uma filosofia marxista propondo os tópicos que seriam de suma importância aos estudos da linguagem e dialogando com duas grandes escolas que os antecederam: a Escola de Genebra, cujo expoente fora Ferdinand de Saussure, e a 
Idealistische Neuphilologie (Filologia Idealista Moderna), cujo expoente fora Karl Vossler.

Vossler quedou-se relativamente desconhecido do público brasileiro, possivelmente mais familiarizado com seus discípulos Leo Spitzer e Erich Auerbach, que na crítica literária representam a chamada escola Estilística. Contudo, foi um proeminente filólogo e romanista da primeira metade do século XX, tendo proposto uma filosofia da linguagem de base idealista publicada na compilação de ensaios Gesammelte Aufsätze zur Sprachphilosophie (Escritos Reunidos para uma Filosofia da Linguagem, sem tradução para o português, doravante referida como Sprachphilosophie). Vossler cita o grande linguista Wilhelm von Humboldt diretamente em sua obra como uma de suas influências. O barão von Humboldt, por sua vez, recebera ampla formação clássica e humanista na qual o homem era compreendido como o centro produtor de seu entorno, noção que ecoará em toda a obra de Vossler, particularmente segundo o conceito Geist ${ }^{l}$.

Faz-se mister, pela importância atribuída por Bakhtin/Volochinov às filosofias de Vossler e Humboldt enquanto tese na construção da síntese marxista, que investiguemos em que ponto jaz a intersecção entre as escolas idealista e marxista. A filosofia marxista da linguagem está bem esquematizada em nossa obra de referência, MFL; contudo, pelo caráter essencialmente ensaístico de Sprachphilosophie e dos escritos de Humboldt, a filosofia da linguagem idealista encontra-se de certa forma diluída na naturalização do conceito estruturante Geist, que perpassa as obras enquanto chave de leitura para o mundo. Tanto Humboldt quanto a Idealistische Neuphilologie são citados em MFL sob a identificação "subjetivismo individualista" (BAKHTIN/VOLOCHINOV, 2014, p. 74), nome dado pelos autores russos para a tradição idealista na filosofia da linguagem, especialmente porque o conceito Geist traz consequências para o estudo da língua enquanto fenômeno individual e coletivo. Os russos assim resumem o subjetivismo individualista:

O psiquismo individual constitui a fonte da língua. As leis da criação linguística - sendo a língua uma evolução ininterrupta, uma criação contínua - são as leis da psicologia individual, e são elas que devem ser estudadas pelo linguista e pelo filósofo da linguagem. Esclarecer o fenômeno linguístico significa reduzi-lo a um ato significativo (e por vezes mesmo racional) de criação individual [...]. A língua é, deste ponto de vista, análoga às outras manifestações ideológicas, em particular às do domínio da arte e da estética. (BAKHTIN/VOLOCHINOV, 2014, p. 74).

Tomemos o psiquismo individual como uma manifestação material do conceito Geist, uma vez que, como já mencionado, sob este termo os alemães colocam o homem como centro e produtor de seu universo, de modo que dão à subjetividade humana (ou à psique humana) todo o poder de criação. Confrontemos a definição dos russos do "subjetivismo individualista" com a definição do próprio Vossler sobre o que seria uma investigação científica apropriada da linguagem:

Mas uma história científica da língua será apenas aquela que compreenda toda a linha causal prática através da estética: de modo que o pensamento linguístico, a verdade

\footnotetext{
${ }^{1}$ Termo normalmente traduzido por "espírito", é um dos pilares da filosofia idealista e engloba a razão, o entendimento e a percepção sensorial. Adiante, abriremos uma discussão especialmente para tratar como este conceito, enquanto chave de leitura para o mundo, estrutura a filosofia da linguagem de Vossler e Humboldt e imprime nelas a dialética hegeliana.
} 
linguística, o gosto linguístico, a intuição linguística ou, como Wilhelm von Humboldt a chama, a forma interna da língua seja esclarecida e compreendida em todas suas mudanças relacionadas física, psíquica, política, econômica e, acima de tudo, culturalmente. (VOSSLER, 1923, p. 19, tradução minha) ${ }^{2}$.

A linha causal seriam eventos que desencadeariam a "evolução" da língua - na verdade, as mudanças linguísticas. Em vários ensaios contidos em Sprachphilosophie, Vossler determina as mudanças linguísticas como objeto de estudo do linguista/filólogo. Conforme declara Vossler em carta a Julius von Schlosser, a história dessas mudanças equivale à sua filosofia da linguagem:

Permita-me fazer alguns acréscimos ainda sobre a execução, a saber, sobre uma filosofia da linguagem sistemática e aplicada. Eu penso que essa seja uma discussão básica das relações nas quais a língua se mantém, se desenvolve e comprova como ação e paixão, trabalho e sentir religiosos, lógicos, econômicos, nacionais, jurídicos, morais, artísticos etc. Da humanidade. Se essa reflexão, que emana do essencial e básico assim como do aparentemente inessencial e acidental, for chamada de filosofia, ou melhor, história da língua, deixo em aberto. (VOSSLER, 1923, p. VIII, tradução e grifos meus) ${ }^{3}$.

Portanto, para que a investigação da intersecção entre as escolas russa e alemã seja bem-sucedida, tomando por base dessa investigação o entendimento de cada uma sobre a relação pensamento-língua, teremos que esquematizar o pensamento de Humboldt e Vossler apoiados no idealismo, num primeiro momento, para depois podermos compará-los com propriedade ao pensamento do Círculo expresso em MFL. Deste modo, a metodologia que aplicaremos dividirá o artigo em duas partes: uma analítica, dedicada ao idealismo alemão, na qual i) abriremos uma breve discussão sobre o conceito Geist, fortemente presente em Vossler e Humboldt, segundo o grande esquematizador do idealismo G. W. F. Hegel e ii) verificaremos a influência deste conceito na filosofia da linguagem dos dois autores supracitados, recorrendo a seus escritos. Desta forma, buscaremos explicitar a relação entre pensamento e língua dentro destes representantes do idealismo alemão. A segunda parte dedicar-se-á a explicitar as relações entre pensamento e língua na filosofia marxista da linguagem segundo o conceito de signo ideológico proposto em MFL, de modo que possamos mapear o quanto a tese (idealismo) contribuiu para a síntese marxista.

Antes de prosseguirmos com nossa investigação, definamos o que estes autores entendem por linguagem e língua. Tanto em russo quanto em alemão, os dois termos são expressos sob o mesmo signo linguístico (iazik, em russo, e Sprache em alemão); ao contrário de Saussure, que fez a diferenciação entre langage, langue e parole (linguagem,

\footnotetext{
${ }^{2}$ Aber eine wissenschaftliche Sprachgeschichte wird erst diejenige sein, die durch die ganze praktische Kausalreihe hindurch zu der ästhetischen gelangt: so dass der sprachliche Gedanke, die sprachliche Warheit, der Sprachgeschmack, das Sprachgefühl oder, wie Wilhelm von Humboldt es nennt: die innere Sprachform in all ihren physisch, psychisch, politisch, ökonomisch und überhaupt kulturell bedingten Wandlungen ersichtlich und verständlich wird.

3 Möge mir vergönnt sein, auch zu der Ausführung, d. h., zu einer systematisch angewandten Sprachphilosophie noch einiges beizutragen. Ich denke mir diese als eine grundsätzliche Erörterung der Verhältnisse, in denen die Sprache zum religiösen, logischen, wirtschaftlichen, nationalen, rechtlichen, sittlichen, künstlerichen usw. Tun und Leiden, Arbeiten und Fühlen der Menschheit steht, sich entfaltet und bewährt. Ob man diese Betrachtungsweise, die auf das Wesentliche und Grundsätzliche überall, also auch im Reich des scheinbar Unwesentlichen und Zufälligen ausgeht, noch Philosphie oder lieber Geschichte der Sprach nennt, lasse ich dahingestellt.
} 
língua enquanto sistema e fala), apenas ao longo das obras é possível entender se os russos e alemães fazem essa diferenciação.

A teoria de Bakhtin/Volochinov parte do signo ideológico, material semiótico produzido pela interação entre indivíduos socialmente organizados. O signo ideológico constitui um fragmento material da realidade e adentra o organismo individual. $O$ universo de signos, como explicado em MFL, é constituído de objetos naturais, ferramentas de produção, gestos, sons, cores, etc., sendo o mais relevante a palavra: "a palavra funciona como elemento essencial que acompanha toda criação ideológica, seja ela qual for" (BAKHTIN/VOLOCHINOV, 2014, p. 38). Para os russos, o termo linguagem engloba diversas manifestações dotadas de valor semiótico, inclusive a linguística, donde concluímos que a língua é uma manifestação específica dentro do campo da linguagem.

Humboldt traz uma inédita definição conceitual para o campo da linguística: a língua não é um produto (ergon/Werk), mas sim uma atividade (energia/Tätigkeit). É possível aproximar essa oposição à clara distinção saussureana entre langue, ou sistema linguístico fechado em si, e langage, atividade de significação que engloba e antecede a produção linguística. Em Vossler, embora não haja emprego de termos distintos para língua e linguagem ou mesmo a reprodução dos termos humboldtianos ergon e energeia, notamos a herança idealista da concepção de língua como atividade, pois sua pesquisa vai além do sistema linguístico em si. Vossler quis buscar nas variações de estilo da expressão do falante a compreensão das motivações do espírito, aproximando a Sprache mais da linguagem do que de um sistema específico e fechado de convenções gramaticais.

Esclarecido esse ponto, daremos, agora, sequência à nossa discussão sobre as relações entre pensamento e língua no Círculo de Bakhtin e no Idealismo Alemão.

\section{O idealismo alemão e o conceito estruturante Geist}

O Geist é, portanto, a essência real e absoluta que se auto sustenta. Todas as formas da consciência até então são abstrações de si mesmas; elas são aquelas em que ele se auto analisa, diferencia seus momentos e no individual permanece. $\mathrm{O}$ isolamento de tais momentos o pressupõe e o continua, ou existe apenas nele - que é a existência. [...] O Geist é, então, consciência acima de tudo, que em si compreende a certeza sensorial, a percepção e o entendimento, enquanto ele mantém o momento na análise de si mesmo; momento em que ele é verdade viva e tornada objeto, e daí abstrai que essa verdade é seu próprio ser-para-si. (HEGEL, 1970, p. 325-326, grifos e tradução minha). ${ }^{4}$

O trecho acima foi retirado do sexto capítulo de Phänomenologie des Geistes (Fenomenologia do Espírito, uma das obras pilares da filosofia hegeliana), intitulado Der Geist (O Espírito). Nele, o autor define Geist diretamente pelo verbo de ligação é, de

\footnotetext{
${ }^{4}$ Der Geist ist hiemit das sich selbst tragende, absolute reale Wesen. Alle bisherigen Gestalten des Bewußtseins sind Abstraktionen desselben; sie sind dies, daß er sich analysiert, seine Momente unterscheidet, und bei einzelnen verweilt.

Dies Isolieren solcher Momente hat ihn selbst zur Voraussetzung und zum Bestehen, oder es existiert nur in ihm, der die Existenz ist. [...] Der Geist ist also Bewußstein überhaupt, was sinnliche Gewißheit, Wahrnehmen und den Verstand in sich begreift, insofern er in der Analyse seiner selbst das Moment festhält, daß er sich gegenständliche, seiende Wirklichkeit ist, und davon abstrahiert, daß diese Wirklichkeit sein eignes Fürsichsein ist.
} 
modo que, dentre as várias passagens do livro que citam o termo, achamos ser esta a mais conveniente para o estudo do conceito.

Primeiramente, Hegel equivale Geist à essência que se auto sustenta. Se o Geist é o essencial, ele é imutável e atemporal; contudo, se desdobra em várias formas dentro dos momentos (tempo). Nestas formas, o Geist se diferencia; quando se diferencia, se particulariza; ao se particularizar, individualiza-se e passa a existir nesta individualidade. Aí, na experiência de se particularizar no tempo, ele se autoanalisa porque é consciente, ou seja, capaz de perceber sensorialmente (espacialmente) e compreender, tomando a si mesmo como objeto do estudo racional de si próprio. Então, ao invés de apenas ser-que não compreende necessariamente perceber a implicação do processo de existir num dado tempo e espaço - ele passa a formar uma imagem de si para si próprio enquanto sujeito deste momento determinado, tornando-se, então, o ser-para-si.

Mas os momentos (em outras palavras, o tempo) existem porque o Geist existe, pois ele é a existência. Logo, o tempo e, consequentemente, o espaço onde esse tempo se desdobra não contém o Geist, mas existem em concomitância a seus momentos de diferenciação. O Geist é toda a existência, por isso é essencial. Tempo e espaço são inerentes à existência; esta, segundo Hegel, é o mesmo que o Geist. Ele não é uma existência amorfa: assume variadas formas ou facetas conforme se desdobra no tempo e espaço. Também não é inconsciente: produz conhecimento ao vivenciar as variadas experiências através das formas. O desdobramento do Geist em variadas formas gera os desdobramentos sociais e materiais do indivíduo, que representam seus momentos. Adiante, Hegel prossegue: "O Geist é a vida costumeira de um povo, enquanto ele é a verdade não mediada; é o indivíduo, que é um mundo." (Idem, p. 326, tradução minha)5.

O Geist se desdobra tanto na experiência individual quanto na coletiva, refletindose nos hábitos e costumes. Se um ou alguns dos indivíduos morrem, nem por isso a sociedade perece ou perde seus hábitos e costumes que a diferenciam de outras. Os próximos indivíduos que nascerem nesta mesma sociedade herdarão hábitos culturalmente equivalentes, dentre eles, a língua (essencialmente, herdarão hábitos por meio dela). Aqui, cabe-nos citar o próprio Wilhelm von Humboldt (2006, p. 2, tradução minha):

[...] apenas na língua o "grande caráter" se desenvolve e, juntamente a ela, enquanto veículo de comunicação de um povo, as individualidades isoladas submergem na manifestação do coletivo. Na prática, um caráter individual manifesta-se apenas por dois meios: pela descendência e pela língua, via caráter do povo em questão. Mas a descendência parece ineficaz antes que um povo tenha se estabelecido através da língua ${ }^{6}$.

Humboldt parece equivaler o "grande caráter" ao Geist, que seria, então, o mínimo divisor comum das variações entre os hábitos de uma determinada sociedade. O conceito de Geist está tão enraizado na cultura alemã que aparece em dicionários monolíngues, consultados por representarem a cristalização do conceito filosófico na cultura letrada:

\footnotetext{
${ }^{5}$ Der Geist ist das sittliche Leben eines Volks, insofern er die unmittelbare Wahrheit ist; das Individuum, das eine Welt ist.

${ }^{6}[\ldots]$ da nur in der Sprache sich der ganze Charakter ausprägt, und zugleich in ihr, als dem allgemeinen Verständigungsvehikel des Volks, die einzelnen Individualitäten zur Sichtbarwerdung des Allgemeinen untergehen, In der That geht ein individueller Charakter nur durch zwei Mittel, durch Abstammung und durch Sprache, in einen Volkscharakter über. Aber die Abstammung selbst scheint unwirksam, ehe durch Sprache ein Volk entstanden ist.
} 
(01) m. 1. a. consciência pensante da humanidade, habilidade de compreensão, compreensão b. perspicácia, vivacidade. 2. mentalidade; atitude mental interior, atitude (Duden, tradução minha) ${ }^{7}$

(02) m. 1. a. consciência pensante, compreensão, razão de um ser humano;

b. mentalidade, atitude

c. $\quad$ sentido, intuito (Karl-Dieter Bünting Deutsches Wörterbuch, tradução minha) ${ }^{8}$

Consciência pensante, razão/compreensão e mentalidade são as entradas comuns entre os dois dicionários, reforçando a nossa leitura do trecho de Hegel supracitado. Para o filósofo, consciência pensante, razão e entendimento ressoam no coletivo tanto quanto o coletivo ressoa no individual, pois toda a filosofia hegeliana é dialética. Enquanto manifestação do Geist, o indivíduo, sempre de acordo com o ethos de seu povo, é o grande criador da realidade: o indivíduo, que é um mundo. Vejamos, agora, como a dialética hegeliana do Geist estrutura as teorias de Humboldt e Vossler.

\section{A influência do conceito estruturante Geist na filosofia idealista da linguagem}

O Geist nos parece o mínimo divisor comum da tradição alemã idealista, da qual fazem parte Humboldt e Vossler, que não dedicam parte de seu espaço para abrir um parêntese a respeito do conceito, procurando defini-lo ou esclarecê-lo; pelo contrário, ele aparece naturalizado no texto desses autores. Isso é indicativo da possibilidade de Humboldt e Vossler presumirem ser seus interlocutores familiarizados com o Geist.

O Geist é, como vimos no trecho de Hegel, a existência, na qual se desdobram dialeticamente o pensamento, a compreensão e a consciência (autoanálise) dentro do tempo-espaço. O Geist é a racionalidade do ser humano. Quando se particulariza numa forma (Gestalt), que é o desdobramento de um de seus momentos, o Geist se individualiza, e neste novo contexto a consciência analisa a si mesma através da certeza sensorial, da percepção e do entendimento. Esse movimento é uma atividade dialética incessante da subjetividade do ser-em-si (Ansichsein), que se objetiva no desdobramento da forma, se auto analisa e depois retorna à subjetividade, agora consciente de si (tornando-se ser-para-si, Fürsichsein). O desdobramento dialético do Geist, que parte de si mesmo para retornar a si transformado após a interação com a objetividade, é a influência essencial do conceito na filosofia da linguagem de Humboldt e Vossler, como veremos a seguir. Nesses autores, o ponto de origem do movimento dialético será sempre a consciência individual.

$\mathrm{Na}$ dialética hegeliana, a consciência entra em contato com a objetividade e se transforma, porém, não é especificado de que maneira a forma interage com sua alteridade. É Humboldt o responsável por desenvolver o papel da linguagem no processo de constituição da consciência, individual e coletiva, e dos referentes do mundo.

\footnotetext{
${ }^{7}$ a. denkendes Bewusstsein des Menschen, Verstandeskraft, Verstand

b. Scharfsinn, Esprit

2. Gesinnung; innere Einstellung, Haltung

Fonte: Duden Online. Acesso em 04. jul. 2016.

8 1. a. denkendes Bewußtsein, Verstand, Vernunft eines Menschen

b. Einstellung, Haltung

c. Sinn, Absicht

Karl-Dieter Bünting Deutsches Wörterbuch, 1996, p. 434.
} 
Humboldt, em seu ensaio Über die Natur der Sprache im allgemeinen (Sobre a natureza da língua em geral 2006), nega a visão mecanicista das línguas, tal seja, aquela em que as palavras são apenas signos arbitrários independentes de seus objetos e conceitos. Para o barão, a arbitrariedade dos sons linguísticos não é completa; apesar de reconhecer que a língua certamente repousa sobre convenções, especulou que a primeira formação das palavras deve ter-se dado pela sensação natural do falante, que encontrou a sensação natural do ouvinte em determinada expressão de sons ligados àquilo que se pretendia expressar. Ou seja, já estamos caminhando pelo terreno da subjetividade ligada aos estudos da língua, que remeteria à analogia entre homem e mundo, assim como daria acesso ao Geist de cada nação (aquele mínimo divisor comum entre os hábitos de um povo).

Humboldt afirma que a palavra certamente é um signo enquanto é usada para representar uma coisa ou conceito no lugar destes, mas sua totalidade não se encerra nessa função. A palavra, diz, é um ser autônomo; sua soma, a língua, consiste num mundo situado entre a objetividade externa e a subjetividade individual. A língua, portanto, não é apenas um sistema cujo acesso e domínio são mecânicos; ela pode ser acessada e dominada desta forma, mas com a perda do valor expressivo que carrega de seu povo. Logo, para compreender a cultura de um povo, devemos compreender sua língua, que "não é nada mais que o complemento do ato de pensar; o esforço de elevar a conceitos claros as impressões externas e aquelas sensações ainda obscuras internas, e de ligar esses conceitos uns aos outros para a criação de novos" (HUMBOLDT, 2006, p. 10, tradução minha $)^{9}$.

Resumindo as ideias desse ensaio: a palavra desempenha papel de signo, mas sua natureza não se encerra nessa função. De mera alusão à coisa representada, a palavra se distingue por sua própria forma sensorial determinada e é capaz de representar diferentes ideias e ângulos da mesma coisa, organizando a nossa variada percepção das diferentes formas do mundo. Humboldt exemplifica: quem pronuncia a palavra "nuvem" não pensa em apenas um tipo ou definição específica de nuvem. A palavra mantém coesa as várias formas do fenômeno natural "nuvem" que podemos experienciar. A língua, portanto, fixa e mantém coesa a comunicação e o ethos de um povo através da palavra.

$\mathrm{Na}$ introdução da coletânea bilíngue brasileira de escritos do autor, encontramos uma boa apresentação de Werner Heidermann das ideias essencialmente humboldtianas:

A linguagem como se manifesta nas línguas individuais representa um sistema amplo e rico demais para ser reduzido a simples veículo de informações. Em outras palavras: a linguagem não é apenas um instrumento utilitário do dia-a-dia. Sua função é facilitar o posicionamento epistemológico do indivíduo. Ela nos permite lidar com o mundo, isto é, nos ajuda a nos orientarmos na infinidade de fatos isolados - o que se faz possível devido à complexidade de seu sistema ante o mundo dos fenômenos. (HEIDERMANN, 2006, p. XXXII-XXXIII, grifos meus).

O pensamento, segundo Humboldt, é complementado pela língua, que dá formas nítidas a impressões externas e internas, permitindo assim o posicionamento epistemológico do sujeito. Ela é capaz de unificar várias formas externas diversas sob um

\footnotetext{
${ }^{9}$ Die Sprache ist nicht anders, als das Complement des Denkens, das Bestreben, die äusseren Eindrücke und die noch dunkeln innere Empfindungen zu deutlichen Begriffe zu erheben, und diese zu Erzeugung neuer Begriffe mit einander zu verbinden.
} 
mesmo signo, assegurando certa unidade comunicativa entre uma subjetividade e outra. $\mathrm{Na}$ língua, também se estrutura o ethos de um povo: para compreendermos uma determinada cultura, devemos mergulhar no estudo de sua língua.

A importância e complexidade dos sistemas linguísticos tornam as diferentes línguas um "organismo" autônomo. Segundo Humboldt, as diferentes facetas de conceitos que carregam as palavras das várias línguas encerram pontos de vista sobre a realidade tão variados e ricos que a discussão de uma língua franca, comum a todos os povos, expressa nada mais do que um preconceito. Assim, melhor seria multiplicar-se as diferentes línguas, pois

[...] o estudo das línguas ensina, além do uso da língua em si, também a analogia - que se expressa na língua - entre os seres humanos e o mundo em geral, e cada nação especificamente; e que o espírito que se revela no mundo por nenhuma dada quantidade de pontos de vista pode ser esgotadamente descrito: antes, cada novo ponto de vista descobre sempre algo novo [...] (HUMBOLDT, 2006, p. 8, tradução minha) ${ }^{10}$.

Retomemos a dialética definição hegeliana de Geist e aquelas dos dicionários de língua alemã consultados: consciência pensante, razão/compreensão e mentalidade. Os momentos do Geist, segundo Hegel, iniciam-se no ser-em-si e resultam em seu posicionamento epistemológico quando retorna a si mesmo da experiência do desdobramento na forma (ser-para-si). Logo, os momentos do Geist (ou da nossa consciência) precisam ser objetivados na forma, e sua experiência precisa ser organizada e significada para transformar o ser-em-si em ser-para-si.

Para Humboldt, a objetivação na forma se dá especialmente por meio da língua, responsável por objetivar a subjetividade individual ao "traduzir" pensamentos na matéria articulada do som para um interlocutor. A língua coloca a subjetividade em contato com sua objetivação na forma ao se ouvir ou ler (caso utilize a matéria articulada da representação gráfica); organiza e significa a experiência individual, facilitando ou mesmo tornando possível o posicionamento epistemológico do sujeito. Por fim, une esse sujeito ao coletivo, uma vez que a palavra, em sua função de signo, é capaz de unificar os variados ângulos e experiências que podemos ter com um objeto, tornando a comunicação possível, além de unir o sujeito enquanto descendência à sua ancestralidade (ao Geist ou "grande caráter" de seu povo).

Neste artigo, trabalhamos com a definição da dialética hegeliana como a atividade incessante da subjetividade de se objetivar e retornar para si transformada desse encontro com o outro e com o mundo. Verificamos como Humboldt postula que essa dialética se realiza por meio da língua. Esta outra definição de Humboldt (2006, p. 98, tradução minha) sobre a língua nos comprova como a noção de atividade (ou dialética) é constituinte da visão linguística do barão: "A língua, percebida em sua verdadeira essência, é algo estável e a cada piscar de olhos transitória. [...] Ela própria não é um produto (érgon), mas sim uma atividade (enérgeia)."11.

\footnotetext{
${ }^{10}[\ldots]$ das Sprachstudium lehrt daher, ausser dem Gebrauch der Sprache selbst, noch die Analogie zwischen dem Menschen und der Welt im Allgemeinen und jeder Nation insbesondre, die sich in der Sprache ausdrückt, und da der in der Welt sich offenbarende Geist durch keine gegebende Menge von Ansichten erschöpfend erkannt werden kann, sondern jede neue immer etwas Neues entdeckt [...]

${ }^{11}$ Die Sprache, in ihrem wirklichen Wesen aufgefasst, ist etwas beständig und in jedem Augenblicke Vorübergehendes. [...] Sie selbst ist kein Werk (Ergon), sondern eine Thätigkeit (Energeia).
} 
Em essência, a noção de linguagem humboldtiana materializa a estrutura dialética do Geist hegeliano. Atividade linguística e atividade dialética do pensamento se complementam, pois uma das formas que a subjetividade encontra para se objetivar é certamente mediante a língua; ademais, dela necessita para organizar sua experiência epistemológica com o mundo em conceitos nítidos e coesos.

Vejamos, agora, como a influência da dialética do Geist hegeliano se dá em Vossler (1923, p. 17-18, tradução minha):

Quando um alemão toma de empréstimo uma expressão do inglês como "made in Germany" e o incorpora ao seu falar, isso acontece por razões de duas ordens distintas: uma série causal prática e uma estética. Os motivos práticos são aqueles que aproximaram e ofereceram a expressão inglesa à língua alemã. São as forças da grande concorrência econômica que a humanidade tem presenciado. Contudo, sozinha, nem toda a potência mundial da Inglaterra nem a mais atraente margem de lucro seria capaz de empurrar essa expressão para a alma do comerciante alemão. Como decisiva dentre as duas, deve a série causal estética ser aquela a vigorar: a saber, o humor, a jocosidade e a ironia do comerciante alemão, como ele considera para si a hostil oferta linguística da expressão cujo significado amargo e original reverte-se em um novo e cuja pronúncia inglesa agora é preenchida com um Geist alemão, até mesmo com um etos alemão - e agora, através desse mesmo Geist que penetrou no estrangeirismo, ele [o comerciante] pode começar a ter simpatia estética. ${ }^{12}$.

A filosofia da linguagem de Karl Vossler pretendeu investigar o que ele denominou "história científica da língua" (seu ponto de vista linguístico passa pela diacronia dos estudos filológicos) segundo a linha causal prática demonstrada pelas mudanças na forma (estética) das línguas através do tempo. Para ele, a linha ou série causal prática que impulsiona as mudanças na língua reflete-se diretamente na série causal estética que é consequência do reposicionamento epistemológico constante do indivíduo perante a coletividade.

Diz Vossler que os fatores objetivos externos não são imperativos sobre a maneira que o indivíduo resolve utilizar-se da língua: as escolhas linguísticas estariam, em verdade, intimamente ligadas à subjetividade, que se expressa através das formas que cada língua oferece. Tais formas teriam por função expressar o humor, a jocosidade, etc. do falante e dialogariam diretamente com sua "alma", que não pode ser outra coisa senão sua consciência alocada epistemologicamente perante a objetividade do mundo.

Para nos ajudar a compreender a raiz do problema filosófico vossleriano, a saber, a manipulação estética da língua a serviço da expressão do falante, voltemos à MFL no

\footnotetext{
${ }^{12}$ Wenn der Deutsche von dem Engländer das Schlagwort made in Germany entlehnt und in seine deutsche Sprache hereinnimmt, so gibt es dafür zwei verschiedene Ordnungen von Gründen: eine praktische und eine ästetische Kausalreihe. Die praktischen Gründe sind diejenigen, die dem Deutschen das englische Schlagwort nahegebracht und angeboten haben. Es sind die Kräfte des grössten wirtschaftlichen Konkurrenzkampfes, den die Menschheit gesehen hat. Allein, dem deutschen Kaufmann dieses Schlagwort in den Mund zu schieben, das vermag weder Englands ganze Weltmacht, noch vermögen es die lockendsten Gewinnberechnungen in der Seele des deutschen Kaufmanns selbts. Es muss als ausschlaggebend die zweite, die ästetische Kausalreihe in Kraft treten: nähmlich der Humor, der Witz, die Ironie des deutschen Kaufmanns, wie er das feindselige Sprachangebot sich betrachtet, dessen bittere, ursprüngliche Bedeutung durch eine neue Deutung umkehrt, dessen englischen Laut mit deutschen Geiste, ja sogar mit deutscher Gesinnung erfüllt und nun durch diesen eigenen Geist hindurch mit der fremden Form ästetisch zu sympathisieren beginnt.
} 
capítulo que discorre sobre a ênfase dada ao estudo da expressão no idealismo alemão. Em MFL, a expressão é definida como "tudo aquilo que, tendo se formado e determinado de alguma maneira no psiquismo do indivíduo, exterioriza-se objetivamente para outrem com a ajuda de algum código de signos exteriores." (BAKHTIN/VOLOCHINOV, 2006, p. 115). Daí deriva a ênfase do idealismo na consciência individual como soberana sobre a atividade exterior e como ponto de partida da dialética transformadora: "Tudo que é essencial é interior, o que é exterior só se torna essencial a título de receptáculo do conteúdo interior, de meio de expressão do espírito." (Idem).

A nosso ver, os russos resumiram o essencial da filosofia vossleriana. Para o alemão, o real executor das mudanças linguísticas é aquele que exerce a linguagem cotidianamente: o falante, cujo psiquismo se objetiva para outrem através da língua. A consciência individual vira, então, foco da investigação linguística, mais especificamente aquilo que motiva a subjetividade a fazer determinadas escolhas estéticas em detrimento de outras. O essencial está no interior, e o exterior se torna relevante apenas enquanto receptáculo do conteúdo interior objetivado na forma linguística.

Tendo compreendido um pouco mais da filosofia de Vossler, foquemos em sua tônica idealista e no quanto dela é estruturado pela dialética do Geist hegeliano. O falante é um indivíduo, e como tal precisa posicionar-se epistemologicamente; para tanto, sua subjetividade, objetivada na forma linguística que realiza a expressão, deve necessariamente significar e organizar cada uma de suas experiências com a objetividade do mundo, gerando a própria transformação. O comerciante alemão do exemplo de Vossler é confrontado com uma oferta linguística "hostil"; segundo seu ethos alemão, ele ressignifica a expressão estrangeira que adentra seu cotidiano pela concorrência econômica, ou seja, toma um posicionamento epistemológico diante da experiência com o mundo. Depois, expressa-se (objetiva-se) por meio de determinadas formas linguísticas que reverberam seu posicionamento perante a sociedade.

No mesmo momento em que a subjetividade se objetiva pela língua, recomeça todo o incessante processo dialético. Para Vossler, as mudanças linguísticas refletem variações na expressão da subjetividade perante o mundo. Caso esse processo, mediado e medido pela língua, prescindisse das transformações dialéticas do sujeito, as formas da língua seriam suficientes para sanar as necessidades de expressão de uma consciência imutável, não havendo mudanças linguísticas. Temos, aqui, mais uma manifestação do desdobramento dialético estrutural do Geist, ou seja, desta consciência que parte de si mesma para voltar a si transformada do contato com a objetividade.

Façamos um resumo da nossa discussão: segundo Hegel, da interação com a alteridade, o ser "retorna" para si mais consciente, ou seja, a consciência retorna para si enriquecida e transformada através do contato com o mundo. No momento seguinte, seu desdobramento já se dará por outra forma e sua experiência será distinta; a cada uma dessas particularizações, a consciência voltará para si transformada, e a cada nova forma gerará uma nova experiência também para a alteridade. Humboldt inaugura a discussão linguística nessa dialética: a língua é o meio essencial pelo qual a consciência se objetiva e organiza sua experiência. Já segundo Vossler, seu sucessor, a discussão linguística essencial é mais especificamente a realização da expressão da subjetividade na forma. Para Vossler, a língua não fica, ela mesma, estática nesta dialética; o movimento de objetivação da expressão do falante através de formas linguísticas por ele apropriadas e ressignificadas soma-se ou choca-se com as formas previamente "ofertadas" pela 
interação social. O falante recolhe à sua subjetividade e adapta para seu uso aquelas formas que são de interesse à expressão de seu ethos, tornando-se o principal responsável pelas mudanças linguísticas.

Destes autores, inferimos que a língua tanto estrutura a forma que a subjetividade assume na hora de se objetivar (se expressar) quanto organiza a experiência dessa subjetividade com a alteridade. Ou seja, a língua estrutura o desdobramento dialético do Geist: quando este é ser-em-si e busca se objetivar na forma, e quando ele torna-se serpara-si ao reorganizar seu posicionamento epistemológico. Esta é, portanto, a relação entre pensamento e língua nos autores idealistas alemães em discussão.

\section{O signo ideológico: relação entre pensamento e língua para o Círculo de Bakhtin}

Da mesma forma que identificamos o conceito Geist como elemento chave que subjaz aos autores idealistas alemães e os particulariza enquanto tais, reconhecemos o conceito de signo ideológico como chave para discutir a relação entre pensamento e língua segundo o Círculo de Bakhtin. Este conceito aparece definido e amplamente discutido no primeiro capítulo de MFL, dedicado a correlacionar a filosofia da linguagem aos estudos das ideologias.

Bakhtin/Volochinov (2014, p. 31,33) definem como criações ideológicas as áreas do conhecimento e cultura: a ciência, a literatura, a religião, a moral e assim por diante. Enquanto criações ideológicas, essas áreas são identificadas por eles como signo, de onde advém o conceito de signo ideológico:

Tudo que é ideológico possui um significado e remete a algo situado fora de si mesmo. Em outros termos, tudo que é ideológico é um signo. Sem signos não existe ideologia. Um signo não existe apenas como parte de uma realidade; ele também reflete e refrata uma outra. Ele pode distorcer essa realidade, ser-lhe fiel, ou apreendê-la de um ponto de vista específico, etc. Todo signo está sujeito aos critérios de avaliação ideológica (isto é, se verdadeiro, falso, correto, justificado, bom, etc.). O domínio do ideológico corresponde ao domínio dos signos: são mutuamente correspondentes. Ali onde o signo se encontra, encontra-se também o ideológico. Tudo que é semiótico possui um valor ideológico.

Todas essas áreas estão intrinsecamente ligadas à comunicação social, da qual o signo é a materialização. A comunicação sempre se dá num terreno interindividual, e a materialização dessa comunicação social é a função pura do signo. $\mathrm{O}$ aspecto semiótico do signo, afirmam os autores, não aparece em outras condições de maneira mais clara e completa do que na língua. A palavra é definida como o signo mais puro e o mais neutro; enquanto cada área possui seus signos e símbolos específicos, a palavra perpassa todas elas, podendo preencher as funções ideológicas do discurso científico, estético, religioso, jurídico, etc., além de estar presente em todos os momentos da vida na comunicação cotidiana. "A palavra é o fenômeno ideológico por excelência." (Idem, p. 36).

A palavra, com toda sua carga semiótica de signo ideológico, integra não apenas a comunicação social como também a consciência individual. Para os russos, nosso psiquismo se estrutura e expressa através do material semiótico, sendo a palavra o principal meio. Figurada no discurso interior, a palavra e os enunciados e enunciações acompanham todos os processos de compreensão e criação do indivíduo. O próprio 
psiquismo só pode se desenvolver através do material semiótico que lhe dá forma e que ele manipula. Todo signo ideológico é um fragmento material da realidade e possui encarnação material: gesto, cor, som, massa física. O que existe de impalpável, como a palavra, nem por isso é imaterial; a própria consciência, para se manifestar, precisa encarnar-se na materialidade do signo, que é um dado social externo.

Para compreender, significar as próprias experiências e atuar na realidade externa, a consciência trabalha aproximando um signo a outros signos. $\mathrm{O}$ signo adentra a consciência individual enquanto material semiótico, produto do meio social, e dentro da consciência compõe o discurso interior que acompanhará o indivíduo ao longo de sua vida. Esse discurso interior é composto por enunciações, que poderão ser objetivadas (expressas) pelo indivíduo ou não; mesmo que não as expresse a um interlocutor real, toda enunciação nasce de uma "situação social mais imediata", citando palavras dos autores. Mesmo que não haja interlocutor real, a enunciação que acompanha o discurso interior sempre levará em consideração um representante médio do grupo social ao qual o indivíduo pertence, e participará de um certo horizonte social determinante dos discursos ideológicos da época a que esse indivíduo pertence, tais como a literatura, ciência, moral, direito, mais recentemente a indústria cultural do cinema e da música, etc. Citando outro termo dos autores, o discurso interior é dirigido diretamente a um "auditório social" bem definido, o que define a palavra enquanto "produto da interação entre locutor e ouvinte" (Ibidem, p. 116-117). A língua é estabelecida em função dos indivíduos sempre em relação a seu meio social, não sendo possível deslocar o foco dos estudos linguísticos e da expressão unicamente para a subjetividade ou para a consciência sem examinar esse meio. A experiência subjetiva se dá mediante o contato com a coletividade, não a priori em relação a ela.

Vemos que o processo dialético é semelhante ao dos idealistas: a consciência entra em contato com sua alteridade e por meio desse contato, particularmente através da língua, organiza sua experiência e então se transforma. Entretanto, opostamente aos alemães, para os autores marxistas a dialética se inicia no terreno social: o signo parte dele e adentra o organismo individual dando forma à consciência, que necessita de material semiótico para operar. A consciência individual não é um dado natural que faz imperar suas leis no mundo material externo; ao contrário, os fragmentos da realidade material penetram, dão forma e suporte à consciência. A língua, figurada no discurso interior através do signo ideológico que compõe as enunciações, é o mais relevante material semiótico que propaga ideologias oriundas do campo da comunicação social. Para Bakhtin/Volochinov (2014, p. 35), "a consciência individual é um fato sociológico" e se estrutura essencialmente pela língua. Esta é a relação entre pensamento e linguagem na filosofia marxista.

\section{Mapeamento Tese/Síntese: contribuições do idealismo ao marxismo na filosofia da linguagem e considerações finais}

Após uma breve exposição das ideias de Hegel, Humboldt, Vossler e Bakhtin/Volochinov, vamos agora analisar quais são os pontos de intersecção entre a filosofia idealista da linguagem e a marxista na relação entre pensamento e língua.

Primeiramente, notamos que os marxistas invertem a dialética idealista em seu ponto de origem. Para Hegel, a dialética se inicia na consciência individual, que se reconhece perante outra consciência e dessa experiência retorna para si transformada. À 
medida que se transforma, volta a se objetivar em novas formas no mundo e retorna novamente a si, num movimento incessante de mútua influência que começa a partir de si mesma, sob meios e em circunstâncias não delimitados. $\mathrm{O}$ desdobramento da consciência em direção ao mundo e de volta a si mesma, em termos abstratos, é a dialética hegeliana.

Humboldt diz que a língua complementa o pensamento no momento em que a consciência se expressa, significa e organiza suas experiências. $O$ barão torna-se $o$ responsável por desenvolver o papel da linguagem no processo de constituição da consciência individual e coletiva e dos referentes do mundo. Num primeiro esboço de linguagem, a sensação natural do falante deve ter encontrado a sensação natural do ouvinte, como se houvesse uma conexão intuitiva prévia entre a matéria articulável do som e consciência subjetiva, conexão essa anterior à convencionalidade do signo linguístico. Há nele, portanto, o mesmo ponto de origem localizado na consciência em direção ao mundo.

A pesquisa estética de Vossler centra-se mais ainda na consciência individual. Pautando sua investigação linguística na expressão, isola como objeto de estudo o falante e as motivações de suas escolhas estéticas, que seriam orientadas pelo conjunto gosto/intuição linguística/forma interna da língua numa junção com a alma ou Geist do falante. Apesar de o falante sofrer influências externas, como no cenário econômico do poderio inglês que nos serviu de exemplo, Vossler o entende como consciente e livre nas escolhas sobre seus processos linguísticos. Novamente, encontramos como ponto de origem da dialética a consciência, soberana sobre seu entorno.

Os autores marxistas invertem esse ponto de origem da dialética. A consciência necessita de material semiótico para operar, e esse material é provido por um conjunto de signos externos a ela. Na língua, através do signo ideológico e opondo um signo a outro, a consciência compõe as enunciações do discurso interior sempre a partir de um horizonte e de um auditório sociais bem definidos. O material semiótico que dá forma à consciência advém da comunicação social, ou seja, é sempre um dado externo a ela. A palavra, oriunda do terreno interindividual da comunicação social, acompanha e torna possível (pois é o material semiótico mais comum da consciência) todos os processos de significação e organização dos posicionamentos epistemológicos do indivíduo.

Ambas escolas trabalham com processos dialéticos. Tanto no idealismo quanto no marxismo, consciência individual e meio social interagem e se transformam mutuamente por influência recíproca. Contudo, a escola alemã dá maior ênfase à "soberania" da consciência sobre a materialidade e sobre os processos linguísticos; já a escola russa afirma que a própria consciência é formada pelo material semiótico que advém da produção ideológica do meio social, e é com este material semiótico vindo do exterior que ela adquire forma para depois influir no meio externo, sempre atrelada ao contexto espaço-temporal de seu auditório e horizonte sociais.

Notemos que Humboldt e Bakhtin/Volochinov convergem no seguinte ponto: para o barão, o signo linguístico (a palavra) é complementar ao ato de pensar, pois torna nítidas impressões externas e sensações internas em conceitos. Ligamos os conceitos uns aos outros para a criação de novos, e desta forma criamos novas relações de significação com o mundo (posicionamento epistemológico). Os russos dizem igualmente que a consciência trabalha opondo um signo a outros, assim criando e ressignificando o material semiótico que proveio da comunicação social. Aqui, novamente, o que distanciará os 
marxistas dos idealistas é o ponto de origem da dialética, que deixa de estar localizado numa consciência soberana ao mundo e passa a estar localizado na produção social ideológica, cujo material semiótico dá forma à consciência.

Estas foram as considerações que levantamos sobre a participação da tese idealista alemã na síntese marxista russa no campo da filosofia da linguagem a partir dos conceitos Geist e signo ideológico. Poderíamos, quem sabe, substituir a palavra "participação" por influência; entretanto, tal troca exigiria averiguar cada uma das críticas que Bakhtin/Volochinov fizeram ao que eles denominaram "subjetivismo idealista", ou seja, à Idealistische Neuphilologie de Karl Vossler e a seu antecessor, Wilhelm von Humboldt. Tal pesquisa seria muito mais extensa que a proposta deste artigo, de modo que nosso propósito foi deixar indicado ao menos uma correlação entre o idealismo alemão e o marxismo russo da primeira metade do século XX.

\section{REFERÊNCIAS}

BAKHTIN, M. M. (VOLOCHINOV). Marxismo e Filosofia da Linguagem: Problemas Fundamentais do Método Sociológico na Ciência da Linguagem. 16. ed. São Paulo: Hucitec, 2014.

BÜNTING, K. Deutsches Wörterbuch. Chur: Isis Verlag, 1996.

DUDEN Online. Berlin: Bibliographisches Institut $\mathrm{GmbH}, 2016$. Disponível em: <www.duden.de>. Acesso em: 04 jul. 2016.

HEGEL, G. W. F. Der Geist. In: Phänomenologie des Geistes. 2. ed. Frankfurt am Main: Suhrkamp, 1970. p. 324-494.

HEIDERMANN, W. Introdução. In: HEIDERMANN, W.; WEININGER, M. J. (Org.). Humboldt: Linguagem, Literatura, Bildung. Florianópolis: Universidade Federal de Santa Catarina, 2006. p. XVII-XLVIII.

HUMBOLDT, W. von. Form der Sprachen. In: HEIDERMANN, W.; WEININGER, M. J. (Org.). Humboldt: Linguagem, Literatura e Bildung. Florianópolis: Universidade Federal de Santa Catarina, 2006. p. 94-119.

. Über die Natur der Sprache im allgemeinen. In: HEIDERMANN, W.; WEININGER, M. J. (Org.). Humboldt: Linguagem, Literatura e Bildung. Florianópolis: Universidade Federal de Santa Catarina, 2006. p. 2-19.

VOSSLER, K. Gesammelte Aufsätze zur Sprachphilosophie. München: Max Hueber Verlag, 1923.

Recebido em: 30/08/2016

Aprovado em: 29/11/2016 